\title{
Optimization of Ceric Ammonium Nitrate Initiated Graft Copolymerization of Acrylonitrile onto Chitosan
}

\author{
Arumugam Shanmugapriya ${ }^{1}$, Ramya Ramammurthy ${ }^{2}$, Venkatachalam Munusamy ${ }^{3}$, \\ Sudha N. Parapurath ${ }^{4}$ \\ ${ }^{1}$ Bharathiar University, Coimbatore, Tamil Nadu, India \\ ${ }^{2}$ Department of Chemistry, Manonmaniam Sundaranar University, Tirunelveli, Tamil Nadu, India \\ ${ }^{3}$ Department of Chemistry, Dravidian University, Kuppam, Andhra Pradesh, India \\ ${ }^{4}$ DKM College, Thiruvalluvar University, Vellore, Tamil Nadu, India \\ E-mail:parsu8@yahoo.com
}

Received March 14, 2011; revised April 21, 2011; accepted May 25, 2011

\begin{abstract}
In the present work, graft copolymerization of polyacrylonitrile onto chitosan has been carried out in the presence of ceric ammonium nitrate redox initiator. Optimization of grafting of polyacrylonitrile onto chitosan was performed by varying the process parameters such as ceric ammonium nitrate (CAN) concentration, polyacrylonitrile concentration and reaction time to study their influence on percent grafting and grafting efficiency. The optimum reaction conditions obtained for grafting of acrylonitrile onto chitosan were reaction time 55 mins, CAN concentration $1 \%$ in Con. $\mathrm{HNO}_{3}$, and polyacrylonitrile concentration $0.75 \mathrm{~mol} / \mathrm{L}$. The characterization of the grafted products by means of FTIR, thermal analysis, X-ray diffraction and scanning electron microscopy furnished the evidence of grafting of polyacrylonitrile onto chitosan.
\end{abstract}

Keywords: Chitosan-g-polyacrylonitrile, Ceric ammonium nitrate, Grafting efficiency, Grafting yield

\section{Introduction}

Chitosan is a unique basic polysaccharide and partially deacetylated polymer of glucosamine obtained after alkaline deacetylation of the chitin [1]. It consists of mainly of $\beta$-[1-4]-2-acetamido-2-deoxy-D-glucose units and is the second most abundant biopolymer on earth after cellulose, widely distributed in crustacean shells and cell walls of fungus $[2,3]$. Chitosan is soluble in dilute acids. The solubility occurs by the protonation of the $-\mathrm{NH} 2$ function on the C-2 position of the D-glucosamine repeat unit, where by the polysaccharide is converted to a polyelectrolyte in acidic media. Chitosan is the only pseudonatural cationic polymer and thus it finds applications in the wastewater treatment. A few review articles on the potential applications of chitosan for pharmaceutical, veterinary medicine, and biomedicine. Chitin and chitosan are widely used for wastewater treatments of polymers experimentally proven that decrease the chemical oxygen demand, total nitrogen and destroy the microbial population [4,5]. However, due to its low mechanical strength and flexible behaviour, chitosan has limited application of water treatment, while addition of synthetic polymers increased its properties tremendously. Besides these applications chitosan has few drawbacks such as acidic solubility, low thermal and mechanical stability. To improve these drawbacks, chitosan can be modified physically and also chemically. Now days, a lot of attention has been paid on chemical modification of chitosan. One such important modification is graft copolymerization [6-9]. Of all possible modifications, graft copolymerisation of vinyl monomers onto natural polysaccharides is quite promising $[10,11]$.

Grafting onto chitosan and its derivatives has been the thrust of researchers. In chitosan, both hydroxyl and amino groups are possible sites for the reaction to incorporate new and desired functional groups. Graft copolymerization of synthetic polymers onto chitosan can introduce desired properties and enlarge the field of the applications by choosing various types of side chains.

In recent years, a number of initiator systems such as APS (ammonium per sulphate), PPS (potassium per sulphate), CAN (ceric ammonium nitrate), FAS (ferrous ammonium sulphate) have been developed to initiate graft copolymerization [6,12-14]. Many investigations have been carried out on the grafted copolymerization of 
chitosan and it is considered to be a promising approach for designing a wide variety of molecular matrices. Graft copolymerization of acrylamide on chitosan using ammonium persulfate as an initiator, was prepared [15].

The effect of temperature, $\mathrm{pH}$ of the medium and concentrations of initiator, chitosan and acrylamide on grafting kinetics and efficiency were established. Graft copolymerization of mixtures of acrylic acid and acrylamide onto chitosan using potassium per sulphate as initiator and methylenebisacrylamide as a cross-linker was carried [16]. Semi-interpenetrating polymer network hydrogel was pre-pared to recognize hemoglobin, by molecularly imprinted method, in mild aqueous media of chitosan and acylami-de in the presence of N, N'-methylenebisacrylamide as the cross linking agent [17].

In the present study chitosan has been graft copolymerized with acrylonitrile with an aim to develop a product, which could be used for wastewater treatment. The effect of reaction conditions such as monomer concentration, initiator concentration and time of reaction have been optimized at constant temperature of $70^{\circ} \mathrm{C}$.

\section{Methods and Materials}

\subsection{Materials}

Chitosan was received from India seafoods, Cochin. Ceric ammonium nitrate, concentrated nitric acid and acrylonitrile were of analytical grade and used as received. The copolymer was characterized using FTIR, TGA, DSC, SEM and XRD. Chitosan-g-polyacrylonitrile was prepared in the presence of UV light assisted oxidative polymerisation using $\mathrm{CAN}$ as an initiator.

\subsection{Preparation of Copolymer}

A $2 \% \mathrm{w} / \mathrm{v}$ solution of chitosan was prepared in $2 \%$ aqueous acetic acid. A solution of $0.1 \mathrm{M}$ CAN in $10 \mathrm{ml}$ of $1 \mathrm{~N}$ nitric acid was added followed by a known amount of acrylonitrile drop by drop with continuous stirring. After a specified time, the reaction was stopped and the product was precipitated using sodium hydroxide solution with vigorous stirring. The precipitate was washed with distilled water for several times and filtered. The percent grafting yield (GY\%) and percent grafting efficiency (GE\%) were calculated as follows:

Grafting efficiency $(\mathrm{GE} \%)=\frac{W_{g}}{W_{g}+W_{i}} \times 100$

Grafting yield $(\mathrm{GY} \%)=\frac{W_{g}-W_{i}}{W_{i}} \times 100$

where,

$W_{\mathrm{g}}=$ weight of grafted copolymer;
$W_{\mathrm{i}}=$ weight of homopolymer (polyacrylonitrile), respectively

\subsection{Characterization}

\subsubsection{FTIR Spectral Studies}

Fourier Transform infrared (FTIR) spectral analyses of the copolymer samples were performed with Thermo Nicolet AVATAR 330 spectrophotometer in 4000-400 $\mathrm{cm}^{-1}$ wave length range, using $\mathrm{KBr}$ pellet method.

\subsubsection{Thermo Gravimetric Analysis}

Thermogravimetric analysis was conducted to measure the thermal weight loss of the copolymers on a SDT Q600 V8.0 Build 95 instrument at a heating rate of $100^{\circ} \mathrm{C}$ per minute in nitrogen atmosphere. The weight losses at different stages were analysed.

\subsubsection{Differential Scanning Calorimetry}

The differential scanning calorimeter (DSC) was used to examine the thermal property of the copolymers. The measurements were performed with NETZSCH DSC $200 \mathrm{PC}$ in a pan Al, pierced lid in the $\mathrm{N}_{2}$ atmosphere at a heating rate of $100 \mathrm{~K} / \mathrm{min}$. The results were recorded and analysed.

\subsubsection{X - Ray Diffraction Studies}

$\mathrm{X}$-ray diffraction (XRD) patterns of the Chitosan-g-acrylonitrile copolymer was studied using X-ray powder diffractometer (XRD - SHIMADZU XD - D1) using a $\mathrm{Ni}$ - filtered $\mathrm{Cu} \mathrm{K \alpha} \mathrm{X-ray} \mathrm{radiation} \mathrm{source.} \mathrm{The}$ relative intensities were recorded within the range of 100 $-900(2 \theta)$ at a scanning rate of $50 \mathrm{~min}^{-1}$.

\subsubsection{Scanning Electron Microscopy (SEM)}

The surface morphology and cross sectional morphology of the copolymer was observed with scanning electron microscopy to verify the compatibility. For the analysis, the samples were cut into pieces of various sizes and wiped with a thin gold-palladium layer by a sputter coater unit (VG-microtech, UCK field, UK) and the cross section topography was analysed with a Cambridge stereoscan 440 scanning electron microscope (SEM, Leica, Cambridge, UK).

\section{Results and Discussion}

The grafting of zwitterionic monomer, N, N-dimethyl-Nmethacryloxy-N-(3-sulfopropyl) ammonium onto chitosan using CAN as redox initiator in acetic acid solution under nitrogen atmosphere was investigated [18]. The effect of reaction condition on the rate of poly (acrylonitrile) grafting onto chitosan under inert atmosphere using 
CAN as initiator was studied [19]. CAN is also reported as a suitable initiator for grafting poly (acryloamide), acrylic acid, poly (4-vinylpyridine) onto chitosan [6].

\subsection{Mechanism}

Graft copolymerization of vinyl monomers onto chitosan is also carried out using redox initiator system such as CAN. This system is used to produce free radical sites which may improve the properties of chitosan material and hence the graft polymerization of acrylonitrile onto chitosan at $60^{\circ} \mathrm{C}$ by using CAN as a initiator is reported. The mechanism as per Don et al. [12]

\section{Step I: Initiation}

1) Direct oxidation

$$
\begin{aligned}
& \mathrm{Cs}+\mathrm{Ce}^{4+} \rightarrow \mathrm{Cs}+\mathrm{Ce}^{3+}+\mathrm{H}^{+} \\
& \mathrm{Cs}+\mathrm{Ce}^{4+} \rightarrow \mathrm{Cs}+\mathrm{Ce}^{3+}+\mathrm{H}^{+}
\end{aligned}
$$

2) Formation of complex

$$
\begin{aligned}
& \text { Complex } \rightarrow \mathrm{Cs}^{+} \mathrm{Ce}^{3+}+\mathrm{H}^{+} \\
& \mathrm{Cs}+\mathrm{M} \leftrightarrow \mathrm{CsM}
\end{aligned}
$$

where $\mathrm{Cs}$ is chitosan chain, $\mathrm{Ce}^{4+}$ and $\mathrm{Ce}^{3+}$ are ceric and cerous ions, respectively. Cs is chitosan chain radical and $\mathrm{M}$ is monomer acrylonitrile.

\section{Step II: Propagation}

$$
\begin{aligned}
& \mathrm{Cs}+\mathrm{M} \leftrightarrow \mathrm{CsM}_{2} \\
& \mathrm{CsM}_{\mathrm{x}} \mathrm{P} \leftrightarrow \mathrm{CsM}_{x} \mathrm{P} \\
& \mathrm{P}=\mathrm{CsM}_{\mathrm{x}}+\mathrm{M}_{x}
\end{aligned}
$$

where $\mathrm{CsM}_{\mathrm{X}}$ is a polyacrylonitrile chain grafted onto with chitosan.

\section{Step 3: Termination}

$$
\begin{aligned}
& \mathrm{CsM}_{\mathrm{x}} \mathrm{P} \leftrightarrow \mathrm{CsM}_{x} \mathrm{P} \\
& \mathrm{CsM}_{\mathrm{x}} \mathrm{P} \leftrightarrow \mathrm{CsM}_{x} \mathrm{P}
\end{aligned}
$$

where $\mathrm{P}$ is the propagating polymer chains

$$
\mathrm{P}=\mathrm{CsM}_{\mathrm{x}}+\mathrm{M}_{x}
$$

\section{Step 4: Chain transfer}

$$
\begin{aligned}
& \mathrm{CsMx}_{\mathrm{x}}+\mathrm{Ce}^{4+} \rightarrow \mathrm{CsM}_{\mathrm{x}}+\mathrm{Ce}^{3+}+\mathrm{H}^{+} \\
& \mathrm{CsM}+\mathrm{M} \rightarrow \mathrm{CsM}+\mathrm{M} \\
& \mathrm{CsM}+\mathrm{P} \rightarrow \mathrm{CsM}+\mathrm{P}
\end{aligned}
$$

The monomer conversion was found to be between 70 and $80 \%$ after $2 \mathrm{~h}$ of reaction at $60^{\circ} \mathrm{C}$. The grafting efficiency increased with the increase in the amount of chitosan.

\subsection{Effect of Reaction Time}

The effect of reaction time on copolymer formation was studied by keeping the initiator concentration, monomer (fixed weight of chitosan and polyacrylonitrile, $0.5 \mathrm{~g}$ ) amount and temperature $\left(70^{\circ} \mathrm{C}\right)$, constant. The yield of copolymer, grafting efficiency and grafting yield have been represented in Figure 1. There is no significant change in graft efficiency with increase in reaction time, whereas, grafting yield is significantly changed with reaction time. As a result, the maximum yield has been found at $55 \mathrm{~min}$. Hence $55 \mathrm{~min}$ was found to be rate of grafting $[20,21]$.

\subsection{Effect of Initiator (CAN) Concentration}

Figure 2 shows the effect of concentration of CAN on the graft copolymerization of polyacrylonitrile onto chitosan by keeping other reaction conditions constant. Both graft yield and grafting efficiency showed an increase with increase in initiator concentration at first, followed by a decrease with further increase of the initiator concentration. The increase of grafting percentage may be ascribed to the increase of macro radicals generated by the attack of more CAN for the saccharide unit of chitosan and therefore, the more active sites of chitosan reacting with polyacrylonitrile. The maximum yield was found at initiator concentration $1.0 \mathrm{~g} / 10 \mathrm{ml}$ of $\mathrm{HNO}_{3}$, hence $1.0 \mathrm{~g}$ was found to be the optimum initiator concentration in this grafting reaction at $70^{\circ} \mathrm{C}$. It was found at lower level of CAN concentration grafting yield is very low, comparatively grafting

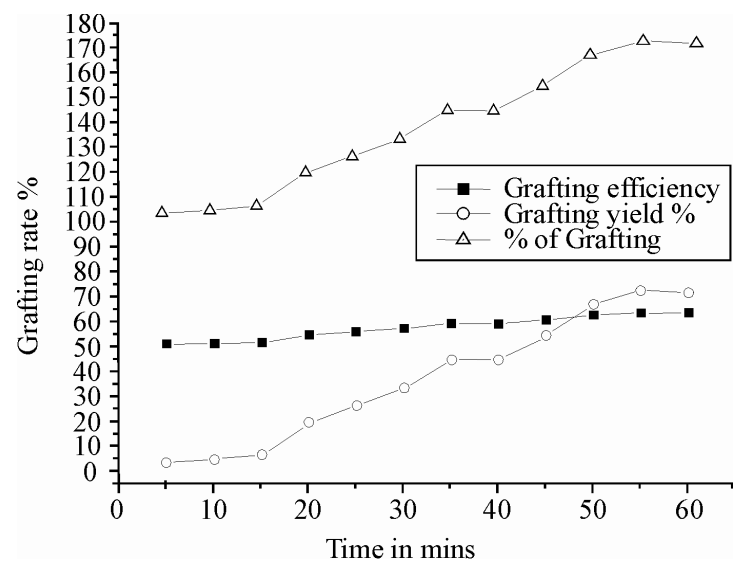

Figure 1. Determination of grafting rate with time

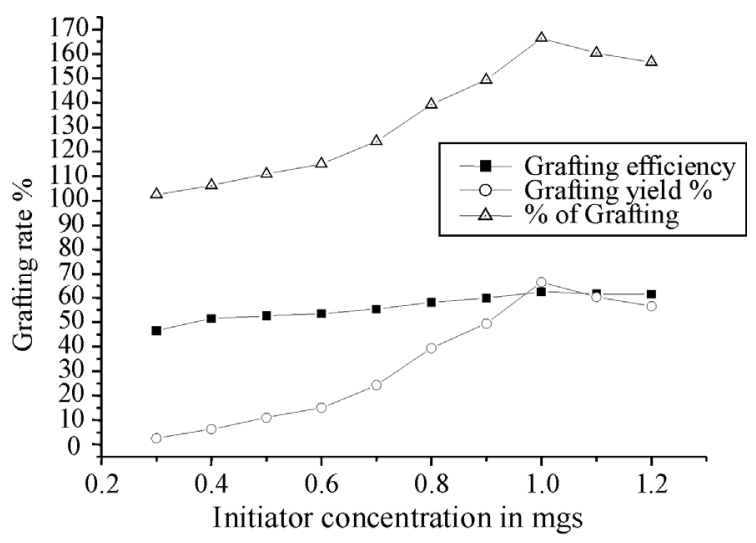

Figure 2. Effect of initiator concentration on copolymerization. 
efficiently is moderate. Further increase of initiator concentration resulted in a decrease of grafting efficiency and grafting yield. It might be due to increase in the number of chitosan free radicals terminated prior to polyacrylonitrile addition $[20,22]$.

\subsection{Effect of polyacrylonitrile concentration}

Figure 3 represents the effect of concentration of polyacrylonitrile on copolymerization reaction (grafting parameters). The grafting efficiency and grafting yield were found to increase with increasing polyacrylonitrile concentration. The maximum grafting yield has been found at $0.75 \mathrm{~mol} / \mathrm{L}$, and then decreased. This decreasing behavior might be because increasing the polyacrylonitrile concentration causes reduction in the active site of chitosan polymer. Additionally, higher the polyacrylonitrile concentration, the primary radicals attack the monomer instead of reacting with the backbone polymer. The excess polyacrylonitrile concentration will shield the graft copolymer which might be inhibiting the rate of copolymerization. Hence, $0.7 \mathrm{~g}$ of polyacrylonitrile was found to be the optimum concentration in this grafting reaction at standard $70^{\circ} \mathrm{C}[20]$.

\subsection{FTIR spectroscopy}

FT-IR is a promising tool to identify unknown substances and to determine the amount of components in a given sample. This test was performed to get authenticated information about the vibrational origin of the nitrile, carbonyl and alcoholic groups of chitosan and polyacrylonitrile. Infra red spectrum of chitosan showed strong peaks at 3388.3 and $1593.4 \mathrm{~cm}^{-1}$ due to $\mathrm{OH}$ stretching and $\mathrm{NH}$ bending vibrations, respectively. The presence of carbonyl absorption peak appeared at 1727.8 $\mathrm{cm}^{-1}$ confirmed the grafting reaction between the chitosan and methyl methaacrylate [23]. On comparing IR spectra of chitosan and chitosan-g-polyacrylonitrile (Figure 4a and $\mathbf{b}$ ), it is observed that the slight shifting of the peak from $3433.9 \mathrm{~cm}^{-1}$ [24] to lower frequency may be due to hydrogen bond formed between chitosan backbones, and from the peaks at 2244.2 and $1252 \mathrm{~cm}^{-1}$ shows the presence of unsaturated nitrogen group and the presence of carbon triple bond confirms the grafting reaction between chitosan and polyacrylonitrile.

\subsection{Thermal Analysis}

The DSC curves of chitosan and the grafted products shown in Figure 5. The appearance of single $T_{\mathrm{g}}$ for copolymer confirms the formation of graft copolymer between chitosan and acrylonitrile. Initial decomposition takes place at $330^{\circ} \mathrm{C}$ for chitosan and $287^{\circ} \mathrm{C}$ for grafted chitosan. The thermal degradation of chitosan occurs at a highest temperature than that of the grafted chitosan, which could indicate that graft thermal degradation occurs before the thermal degradation of the main chitosan's chain. Thus the thermal degradation rate related to grafted chitosan copolymer is higher than the pure chito san. Also this result showed that the degree of crystallinity for the chitosan-g-polyacrylonitrile was lesser than the pure chitosan, which was consistent with the result of $\mathrm{X}$-ray diffraction.

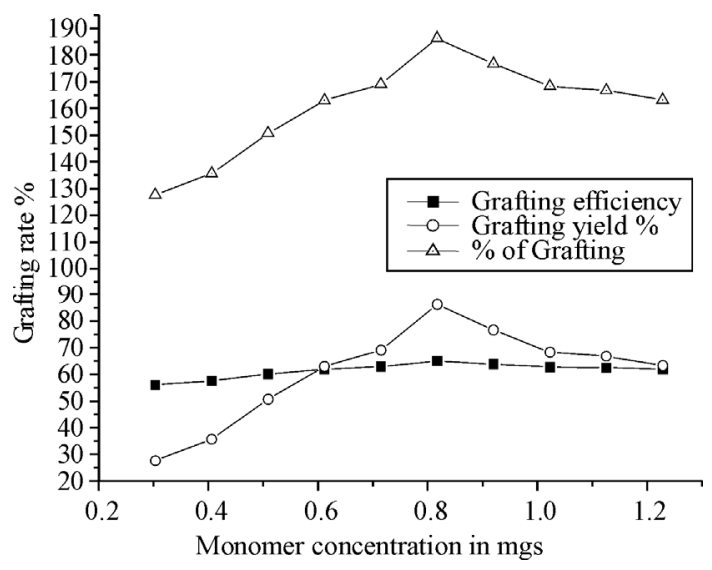

Figure 3. Effect of monomer amount of copolymer formation.

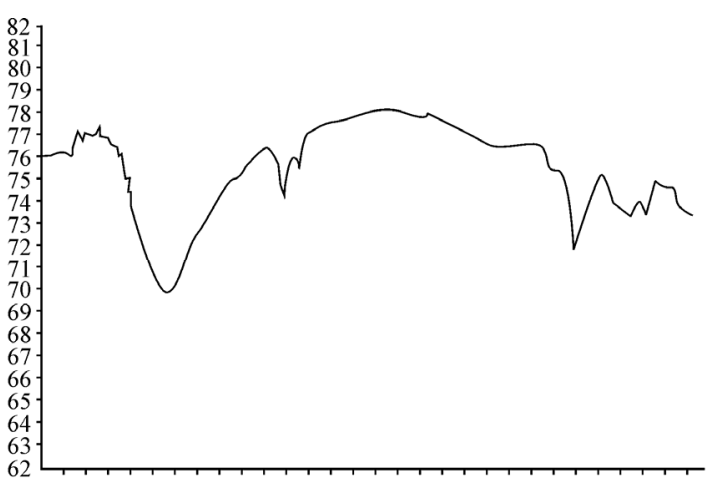

(a)

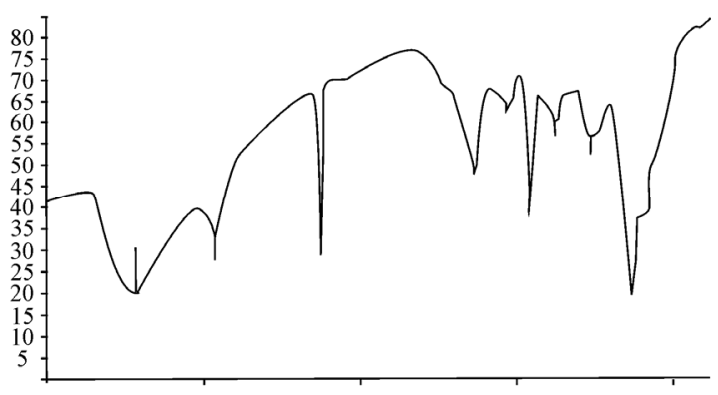

(b)

Figure 4. FTIR spectra of chitosan (a) and grafted chitosan (b). 
The TG analysis of chitosan and copolymer are shown in the Figure 6 Figure 6 shows that about $50 \%$ initial weight of ungrafted chitosan is lost at $332^{\circ} \mathrm{C}$, whereas in grafted chitosan, $50 \%$ of the initial weight is lost at $380^{\circ} \mathrm{C}$, which taken as a initial decomposition temperature. The $50 \%$ weight decomposition temperature of the copolymer is higher compared to pure chitosan. The residue percent of the grafted chitosan at the maximum temperature is decreased when compared to ungrafted chitosan, this decrease is proportional to the graft $\%$. These results revealed that grafting enhances the initial decomposition temperature of the copolymer when compared to the original chitosan.

\subsection{X-ray Diffraction Studies}

The X- ray diffraction spectra of pure chitosan and chitosan-g-PAN were measured, which were shown in Figure 7(a) and (b). The chitosan exhibits two diffraction peaks at $11^{\circ}$ and $20^{\circ}$, which are characteristics of the hydrated crystalline structure of chitosan, whereas in grafted chitosan, there is a broad peak in the region of $42-45^{\circ}$ which may have contributed from both chitosan and polyacrylonitrile. The typical crystalline peak of chitosan that appeared at $2 \theta-20^{\circ}$ decreases when polyacrylonitrile is grafted on to chitosan. This phenomenon was due to the strong interaction (formation of covalent bond) between chitosan and acrylonitrile. In other word, copolymerization improved the compatibility between CS and polyacrylonitrile.

\subsection{Morphological Studies of Copolymer}

The scanning electron micrograph of pure chitosan and chitosan-g-polyacrylonitrile is shown in the Figure 8 (a) and (b). The SEM image of chitosan (Figure 8(a)) shows smooth surface, because there are stronger interaction between the chitosan molecules. The copolymerization of polyacrylonitrile modified the surface morphology of chitosan significantly making it useful for water treatment. The SEM image of copolymer revealed that uniform distribution of polyacrylonitrile might be improving that characteristic nature of chitosan as well as polyacrylonitrile. This characteristic membrane may responsible to allow water with greater adsorbing property [25].

\section{Conclusions}

Graft copolymer of chitosan-g-polyacrylonitrile was successfully synthesized by free radical polymerization using the initiator ceric ammonium nitrate. The graft copolymer was characterized by FTIR and XRD, which
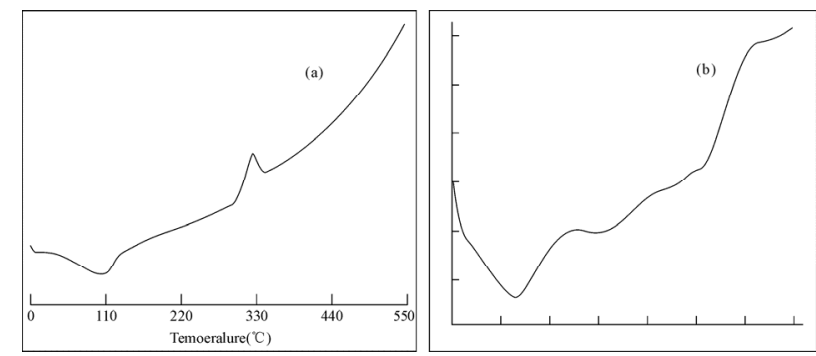

Figure 5. DSC thermograms of chitosan (a) and chitosan-g-polyacrylonitrile (b).

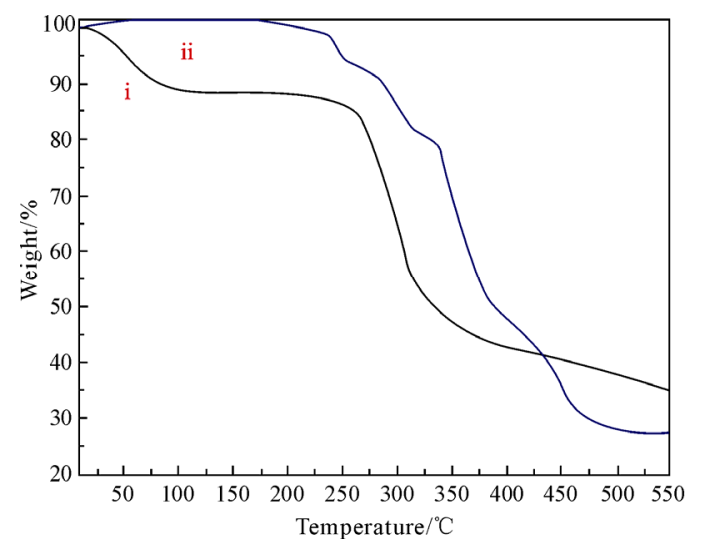

Figure 6. Thermogravimetric analysis (TGA) of pure chitosan (i) and the grafted copolymer (ii).

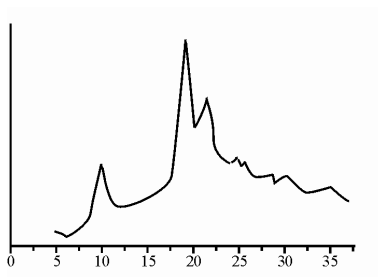

(a)

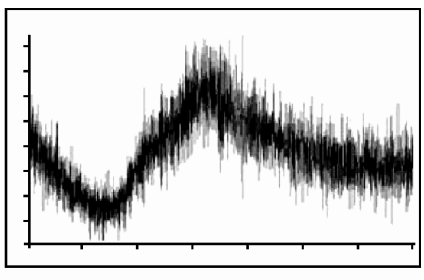

(b)
Figure 7. X- ray diffraction spectra of pure chitosan (a) and chitosan- g- PAN (b).

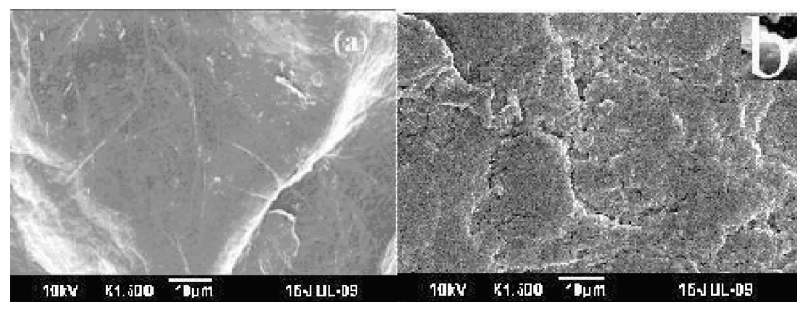

Figure 8. SEM image of pure chitosan (a) and grafted chitosan (b).

elucidated the structure changes in comparison with pure chitosan. The SEM micrograph of grafted chitosan showed fractured and rough surface morphology providing better adsorption sites. TGA and DSC analysis re- 
vealed that graft copolymer had more thermal stability. The results of grafting yield and grafting efficiency from the graph confirm that graft copolymerization has been successively achieved.

\section{Acknowledgements}

The authors thank the authorities of DKM college, Thiruvalluvar University, Vellore, Tamil nadu, India for the support.

\section{References}

[1] L. Dambies, C. Guimon, S. Yiacoumi and E. Guibal, "Characterization of Metal Ion Interactions with Chitosan by X-ray Photoelectron Spectroscopy," Colloids and Surfaces A: Physiochemical and Engineering Aspects, Vol. 177, 2001, pp. 203-214. doi:10.1016/S0927-7757(00)00678-6

[2] P. K. Dutta, J. Dutta, M. C. Chattopadhyaya and V. S. Tripathi, "Chitin and Chitosan: Novel Biomaterials Waiting for Future Development," Journal of Polymer Materials, Vol. 21, No. 3, 2004, pp. 321-333.

[3] N. K. Mathur and C. K. Narang, "Chitin and Chitosan, Versatile Polysaccharides from Marine Animals," Journal of Chemical Education, Vol. 67, 1990, pp. 938-942. doi:10.1021/ed067p938

[4] H. Meyer, W. Butte and M. Schlaak, "Chitosan in Wastewater Treatment," Advances in Chitin Science, Vol. 4, 2000, pp. 153-158.

[5] P. N. Sudha, in Se-Kwon Kim, Ed. "Chitin, Chitosan, Oligosaccharides and Their Derivatives," CRC Press, 2010, pp. 561-576.

[6] H. Caner, H. Hasipoglu, O. Yilmaaz and E. Yilmaaz, "Graft Copolymerization of 4-Vinylpyridine onto Chitosan 1. By Ceric Ion Initiation," European Polymer Journal, Vol. 34, 1998, pp. 493-497.

[7] M. Y. Pedram and J. Retuert, "Homogeneous Grafting Reaction of Vinyl Pyrrolidone onto Chitosan," Journal of Applied Polymer Science, Vol. 63, No. 10, 1997, pp. 1321-1326. doi:10.1002/(SICI)1097-4628(19970307)63:10<1321::AI D-APP11>3.0.CO;2-7

[8] K. L. Shantha, U. Bala and K. P. Rao, "Tailor-Made Chitosans for Drug Delivery," European Polymer Journal, Vol. 31, No. 4, 1995, pp. 377-382. doi:10.1016/0014-3057(94)00177-4

[9] T. Sun, W. Xie and P. Xu, "Superoxide Anion Scavenging Activity of Graft Chitosan Derivatives," Carbohydrate Polymers, Vol. 58, No. 4, 2004, pp. 379-382. doi:10.1016/j.carbpol.2004.06.042

[10] Srivastava, J. Tripathy, M. M. Mishra and K. Behari, "Modification Of Guar Gum Through Grafting Of 4-Vinyl Pyridine Using Potassium Peroxymonosulphate/ Ascorbic Acid Redox Pair," Journal of Applied Polymer Science, Vol. 106, No. 2, 2007, pp. 1353-1358. doi:10.1002/app.26575
[11] J. Tripathy, D. K. Mishra, A. Srivastava, M. M. Mishra and K. Behari, "Synthesis Of Partially Carboxymethylated Guar Gum-g-4-Vinyl Pyridine and Study of Its Water Swelling, Metal Ion Sorption and Flocculation Behaviour," Carbohydrate Polymer, Vol. 72, No. 3, 2008, pp. 462-472. doi:10.1016/j.carbpol.2007.09.014

[12] T. M. Don, C. F. King and W. Y. Chiu, "Synthesis and Properties of Chitosan-modified Poly (vinyl acetate)," Journal of Applied Polymer Science, Vol. 86, No. 12, 2002, pp. 3057-3063. doi:10.1002/app.11329

[13] M. Y. Pedram, J. Retuert and R. Quijada, "Hydrogels Based on Modified Chitosan, 1. Synthesis and Swelling Behavior of Poly (acrylic acid) Grafted Chitosan," Macromolecular Chemistry and Physics, Vol. 201, No. 9, 2000, pp. 923-930. doi:10.1002/1521-3935(20000601)201:9<923::AID-MA CP923>3.0.CO;2-W

[14] H. S. Blair, J. Guthrie, T. K. Law and P. Turkington, "Chitosan and Modified Chitosan Membranes I. Preparation and Characterisation," Journal of Applied Polymer Science, Vol. 33, No. 2, 1987, pp. 641-656. doi:10.1002/app.1987.070330226

[15] A. E. Mochalova, N. V. Zaborshchikova, A. A. Knyazev, L. A. Smirnova, V. A. Izvozchikova, V. V. Medvedeva and $\mathrm{Yu}$ D. Semchikov, "Graft Polymerization of Acrylamide on Chitosan: Copolymer Structure and Properties," Polymer Science Series A, Vol. 48, No. 9, 2006, pp. 918-923. doi:10.1134/S0965545X06090069

[16] A. E. Mochalova, L. A. Smirnova, S. D. Zaitsev, Yu D. Semchikov, I. I. Zaitseva and G. Pavlov, "Hydrodynamic and Molecular Characteristics of Graft Polymers of Chitosan with Acrylamide," Polymer Science Series B, Vol. 49, No. 9, 2007, pp. 232-235. doi:10.1134/S1560090407090059

[17] Y. Q. Xia, T. Y. Guo, M. D. Song, B. H. Zhang and B. L. Zhang, "Hemoglobin Recognition by Imprinting in Semi-interpenetrating Polymer Network Hydrogel Based on Polyacrylamide and Chitosan," Biomacromolecules, Vol. 6, No. 5, 2005, pp. 2601-2606. doi:10.1021/bm0503241

[18] J. Zhang, Y. Yuan, J. Shen and S. Lin, "Synthesis and Characterization of Chitosan grafted Poly $(\mathrm{N}$, $\mathrm{N}$-dimethyl-N-methacryloxyethyl-N-(3-sulfopropyl)amm onium) Initiated by Ceric (IV) ion," European Polymer Journal, Vol. 39, No. 4, 2003, pp. 847-850. doi:10.1016/S0014-3057(02)00286-0

[19] Pourjavadi, G. R. Mahdavinia, M. J. Zohuriaan-Mehr and H. Omidian, "Modified Chitosan. I. Optimized Cerium Ammonium Nitrate-induced Synthesis of Chitosan-graftpolyacrylonitirle," Journal of Applied Polymer Science, Vol. 88, No. 8, 2003, pp. 2048-2054. doi:10.1002/app.11820

[20] J. M. Joshi and V. K. Sinha, "Ceric Ammonium Nitrate Induced Grafting of Polyacrylamide onto Carboxymethyl Chitosan," Carbohydrate Polymer, Vol. 67, No. 3, 2007, pp. 427-435. doi:10.1016/j.carbpol.2006.06.021

[21] Y. N. Sharma, V. G. Gandhi and I. S. Bhardwaj, "Investigations on the Kinetics of Copolymerization of Vinyl 
Acetate with Acrylonitrile by $\mathrm{Co}(\mathrm{acac})_{3}-\mathrm{Al}\left(\mathrm{C}_{2} \mathrm{H}_{5}\right)_{3}$ Catalyst System," Journal of Polymer Science: Polymer Chemistry Edition, Vol. 18, No. 1, 1980, pp. 59-64. doi:10.1002/pol.1980.170180106

[22] J. S. Shukla and G. K. Sharma, "Graft Copolymerization of Methyl Methacrylate onto Wool Initiated by Ceric Ammonium Nitrate-Thioglycolic Acid Redox Couple in Presence of Air. IV," Journal of Polymer Science Part A: Polymer Chemistry, Vol. 25, No. 2, 1987, pp. 595-605. doi:10.1002/pola.1987.080250213

[23] C. Radhakumary, Prabha D. Nair, C. P. Reghunadhan Nair and S. Mathew, "Biopolymer Composite of Chitosan and Methyl Methacrylate for Medical Applications," Trends Biomaterials and Artificial Organs, Vol. 18, 2005, pp. 117-124.

[24] D. K. Mishra, J. Tripathy, M. M. Mishra, A. Srivastava and K. Behari, "Graft Copolymer (Chitosan-G-N-Vinyl Formamide): Synthesis And Study Of Its Properties Like Swelling, Metal Ion Uptake And Flocculation," Carbohydrate Polymer, Vol. 74, No. 3, 2008, pp. 632-639. doi:10.1016/j.carbpol.2008.04.015

[25] [26] A. J. M. Al-Karawi, Z. H. J. Al-Qaisi, H. I. Abdullah, A. M. A. Al-Mokara and D. T. Ajeel Al-Heetimi, "Synthesis, Characterization Of Acrylamide Grafted Chitosan And Its Use In Removal Of Copper(II) Ions From Water," Car-bohydrate Polymer, Vol. 83, No. 2, 2011, pp. 495-500. doi:10.1016/j.carbpol.2010.08.017 